\title{
СТАНЦИЯ, \\ ЦЕХ, ЦЕНТР: \\ космическая связь \\ в "Медвежьих Озерах"
}

л.Павлова

DOI: $10.22184 / 2070-8963.2020 .89 .4 .16 .19$

В июне этого года исполнилось 25 лет филиалу ФГУП "Космическая связь" (ГП КС) - Центру космической связи (ЦКС) "Медвежьи Озера". При этом история Центра восходит к 1967 году, когда на территории опытного полигона Особого конструкторского бюро Московского энергетического института (ОКБ МЭИ) в Медвежьих Озерах Московской области был построен первый спутниковый приемопередающий комплекс системы "Орбита", который первоначально был назван "Станцией космической связи", потом "Цехом космической связи "Орбита-1". Сегодня ЦКС "Медвежьи Озера" - один из крупнейших телепортов России. Пролистаем страницы его истории.

\section{ИСТОРИЯ ОРБИТАЛЬНОГО ЦЕХА}

1 мая 1965 года в СССР был проведен эксперимент по ретрансляции программ Центрального телевидения через высокоэллиптический спутник связи "Молния-1" на Дальний Восток. Спутниковая линия связи между Москвой и Владивостоком предназначалась также для передачи группового спектра 60 телефонных каналов. Для более широкого охвата телевещанием, а также многоканальной телефонной и телеграфной связью удаленных регионов в СССР приступили к строительству гигантской коллективной приемной сети "Орбита". В 1967 году первые 20 станций "Орбита" были введены в эксплуатацию. А ключевым звеном системы стала "Станция космической связи" в Медвежьих Озерах.

Регулярную работу система "Орбита" начала 2 ноября 1967 года, с открытием первой очереди телевизионного комплекса в Останкино. Передачи предназначались для районов Крайнего Севера, Дальнего Востока и Средней Азии. Первоначально в системе "Орбита" использовались спутники "Молния-1", работающие на дециметровых волнах, на частотах 800-1000 МГц. Последующие модификации - спутники
"Молния-2" - работали в рекомендованном международными стандартами диапазоне сантиметровых волн. В дальнейшем в системе поясного телевещания стали использоваться космические аппараты с выведением на геостационарную орбиту - "Радуга", "Экран", "Горизонт", "Радуга-1", "Экспресс", "Радуга-1м".

В 70-е годы "Станция космической связи" в Медвежьих Озерах вошла в состав вновь созданного предприятия "Центр космической связи", основной задачей которого было развитие спутниковой связи и вещания в стране в интересах народного хозяйства. В эти годы из Медвежьих Озер осуществлялось постоянное вещание телевидения и телефонии на сеть приемных стан ций "Орбита" в Сибири, Средней Азии и на Дальнем Востоке; была налажена работа в составе международной системы спутниковой связи "Интерспутник". Сотрудники ЦКС совместно со специалистами Министерства связи принимали участие в строительстве и эксплуатации станций космической связи за рубежом.

В 1974 году с использованием технических средств цеха "Орбита-1", а также спутников связи "Интелсат" и "Молния-3" впервые был организован 
канал прямой правительственной связи "Москва сША", который успешно работал в течение нескольких лет.

В 1979 году предприятие "Центр космической связи" было переименовано в Союзный узел радиовещания и радиосвязи № 9 (СУР-9), а "Станция космической связи" в Медвежьих Озерах преобразована в Цех космической связи "Орбита-1".

В 1980 году технический парк Цеха космической связи "Орбита-1" был модернизирован в связи с участием в передаче репортажей "Олимпиады-80" в Австралию, Японию и страны Ближнего Востока. С этого момента предприятие становится крупным телепортом, позволяющим организовывать спутниковые каналы связи со станциями, расположенными по всему миру.

\section{ЦЕНТР ВЧЕРА И СЕГОДНЯ}

В 1995 году Цех космической связи "Орбита-1" обрел официальный статус филиала ГП КС и свое нынешнее название - Центр космической связи "Медвежьи Озера". С этого момента предприятие развивалось семимильными шагами: в первые же годы были проведены работы по благоустройству территории; на площадке ЦКС с участием специалистов центра смонтированы и оснащены оборудованием восемь новых земных станций для работы в различных частотных диапазонах на современных космических аппаратах; внедрена компьютерная сеть управления и мониторинга систем наведения антенн, передающего и приемного оборудования; построена и введена в эксплуатацию волоконно-оптическая линия связи от Технического центра "Шаболовка" ГП КС до ЦКС "Медвежьи Озера". Это позволило в дальнейшем отказаться от доставки сигналов по радиорелейным линиям связи и обеспечить выполнение требований ведущих телекомпаний России к ГП КС по организации качественной и надежной передачи цифрового вещания. Кроме того, в 1997 году в ЦКС были проведены работы по строительству двух высоковольтных линий электропередач, трансформаторной подстанции и внедрению трех установок бесперебойного электропитания (UPS), что позволило центру выйти на уровень электроснабжения, соответствующий 1-й категории. В 2013 году для повышения надежности электроснабжения в дополнение к существующей дЭС-500 БАМ приобретена новая дизель-генераторная установка ДГУ Wilson $640 \mathrm{kBT}$.

В 1998 году ЦКС успешно осуществил прием репортажей с Олимпийских игр в Австралии для спортивных редакций телекомпаний 1 Канал, ВГТРК и НТВ.

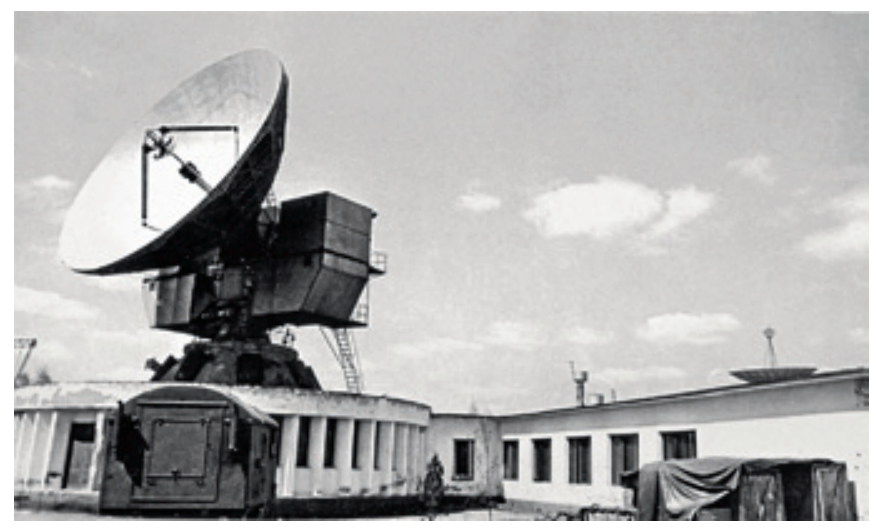

В 90-е годы в "Медвежьих Озерах" активно проводились сравнительные испытания новых видов оборудования различных зарубежных фирм с целью использования цифровых технологий для спутниковых каналов связи. В рамках этих работ в 1998 году были проведены испытания оборудования фирм CLI, Wegener, Tandberg и др. для передачи цифрового ТВ через транспондеры отечественных спутников серии "Горизонт".

С 1998 года по настоящее время специалисты ЦКС "Медвежьи Озера" проводят большую работу по созданию спутниковой системы связи "Юпитер", основной задачей которой является организация спутниковых каналов связи между объектами сети для мультисервисного обмена в интересах органов государственной власти Российской Федерации при решении задач государственного управления.

В 2001 году центром организована первая в России спутниковая трансляция программ телевизионных компаний НТВ, ТНТ и Рен ТВ в цифровом формате.

В рамках государственной программы перевода федеральных телепрограмм на цифровые методы подачи и распределения с ноября 2004 года в ЦКС "Медвежьи Озера" начато вещание федеральных программ в цифровом формате на европейскую часть России, Урал и Западную Сибирь через спутник "Экспресс-АM1".

В 2003 году ГП КС в рамках работ по созданию комплексов, использующих спутниковую связь многоуровневых телемедицинских систем для борьбы с инфекционными заболеваниями, при участии специалистов ЦКС "Медвежьи Озера" была разработана и изготовлена мобильная телемедицинская лаборатория МТЛ-5852 на базе автомобиля КамА3-43118K.

В 2005-2006 годах на базе ЦКС велись разработка, испытание и внедрение отечественной системы условного доступа "Роскрипт", предназначенной 


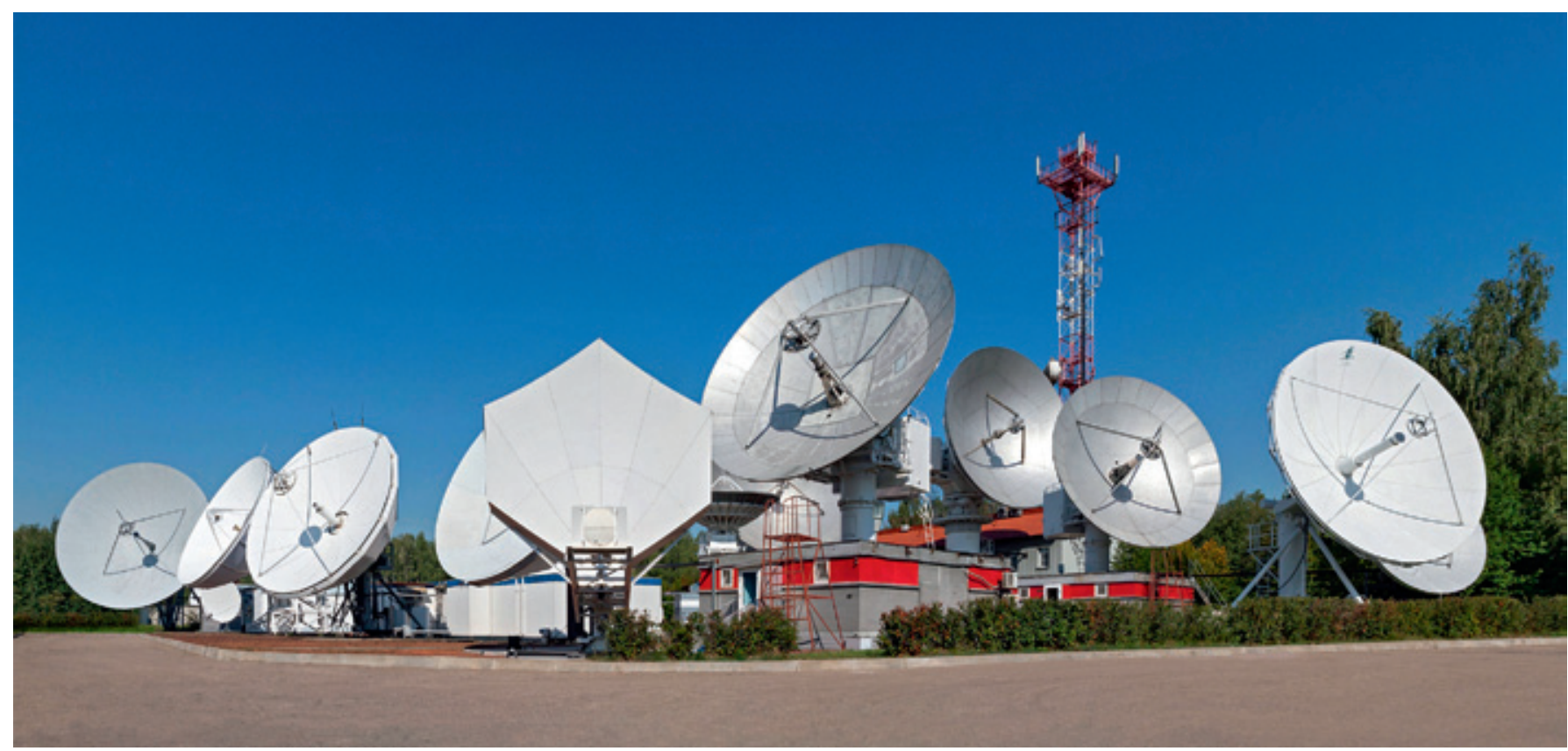

для ограничения несанкционированного доступа к ТВ-контенту, распространяемому через спутниковые каналы. В том же году началось тестовое вещание телевизионных программ в формате MPEG-4.

В 2007 году в ЦКС введен в эксплуатацию резервный центр компрессии (РЦК), предназначенный для формирования цифровых пакетов федеральных телевизионных программ в случае выхода из строя основного центра компрессии, расположенного в ТЦ "Шаболовка". РЦК успешно выполнял функциональные задачи до момента прекращения аналогового вещания в 2019 году.

В мае 2009 года специалисты центра обеспечили ТВ-вещание международного песенного конкурса "Евровидение-2009" из Москвы на страны Европы в HD-формате.

C 2011 года ЦКС "Медвежьи Озера" участвует в реализации решения Правительственной комиссии по телевидению и радиовещанию о распространении на территорию Российской Федерации сигналов цифровых мультиплексов. В рамках этого проекта в ЦКС проведена модернизация каналообразующего комплекса, создана основанная на новых принципах система многооконного мониторинга ТВ-сервисов, построена и введена в работу новая земная станция спутниковой связи.

В 2014 году в эксплуатацию введено второе полукольцо ВОЛС, позволившее заметно повысить надежность системы передачи сигнала между ТЦ "Шаболовка" и ЦКС "Медвежьи Озера". В 2014 году с непосредственным участием средств центра обеспечена трансляция репортажей с зимних Олимпийских игр в г. Сочи.

В 2015 году проведен комплексный аудит технической базы ЦКС "Медвежьи Озера", а в период с 2015 по 2020 год проводятся мероприятия по модернизации, дооснащению и дальнейшему развитию ЦКС с целью предоставления услуг заказчикам на самом современном уровне: проводится замена устаревших моделей передатчиков на современные (твердотельные); проклады ваются и вводятся в работу оптические линии передачи сигналов до земных станций; разрабатываются и вводятся в работу системы компьютерного управления и мониторинга технологических процессов.

Для повышения оперативности контроля и обеспечения высокого качества предоставляемых услуг в 2017-2018 годах подготовлены и введены в эксплуатацию системы мониторинга электропитания и цифровых теле- и радиоканалов, а также дистанционного контроля сигналов звукового сопровождения и радиовещания.

В 2017 году с целью распространения в мире объективной информации о России организовано вещание радиопрограмм международного информационного агентства "Россия сегодня", в обеспечении вещания которого важную роль играет и ЦКС "Медвежьи Озера".

2018 год прошел в ЦКС под знаком особо важных работ: центр участвовал в обеспечении качественной и бесперебойной трансляции выборов Президента Российской Федерации, репортажей 
с Чемпионата мира по футболу и других знаковых мероприятий.

В разное время ЦКС "Медвежьи Озера" принимал у себя всероссийские чемпионаты по скоростному монтажу VSAT.

\section{ИНФРАСТРУКТУРНЫЙ РАКУРС}

Сегодня в состав наземной инфраструктуры ЦКС "Медвежьи Озера" входят 16 приемо-передающих земных станций спутниковой связи с антенными системами от 4 до 16 м. Оснащенные современным оборудованием станции позволяют организовывать каналы спутниковой связи в различных частотных диапазонах на российских и зарубежных спутниках связи в орбитальных позициях от $14^{\circ}$ з. д. до $103^{\circ}$ в. д. В центре расположены две территориально разнесенные волоконно-оптические линии связи общей емкостью 12,5 Гбит/с, работающие в режиме резервирования друг друга и обеспечивающие надежную широкополосную связь ЦКС с центром формирования программ ГП КС в ТЦ "Шаболовка" и с ТЦ КМТ в Останкино. Центр также имеет прямой выход на узел коммутации ОАО "Комкор". Все это позволяет связать ЦКС "Медвежьи Озера" с любым источником сигналов Московского региона. Кроме того, волоконно-оптическая линия связи между ЦКС и Щелково (Московская область) позволяет организовать каналы связи с основными объектами города - администрацией, ОАО "ЦентрТелеком", спортивным комплексом им. Н.Озерова и др.

В центре создана мощная инфраструктура энергоснабжения: четыре высоковольтных фидера $(2 \times 10 \mathrm{kB}$ и $2 \times 6$ кB) обеспечивают резервируемое энергопитание объекта. Для надежной работы технологического оборудования в ЦКС "Медвежьи Озера" реализована система бесперебойного питания общей мощностью 550 кВА. В случае форсмажорных обстоятельств электропитание объекта может быть обеспечено от автономной дизельной электростанции ДГУ Wilson 640 кВт.

Особое место в структуре ЦКС занимает оборудование резервного центра компрессии. Задача этого комплекса - обеспечить формирование потоков федеральных телерадиопрограмм на все вещательные зоны страны в случае возникновения аварийной ситуации на основном центре компрессии, расположенном на Шаболовке. На территории центра также находится радиорелейная мачта высотой $48 \mathrm{~m}$, которая позволяет организовать релейные каналы связи с телецентром "Останкино" и разместить системы других видов связи.

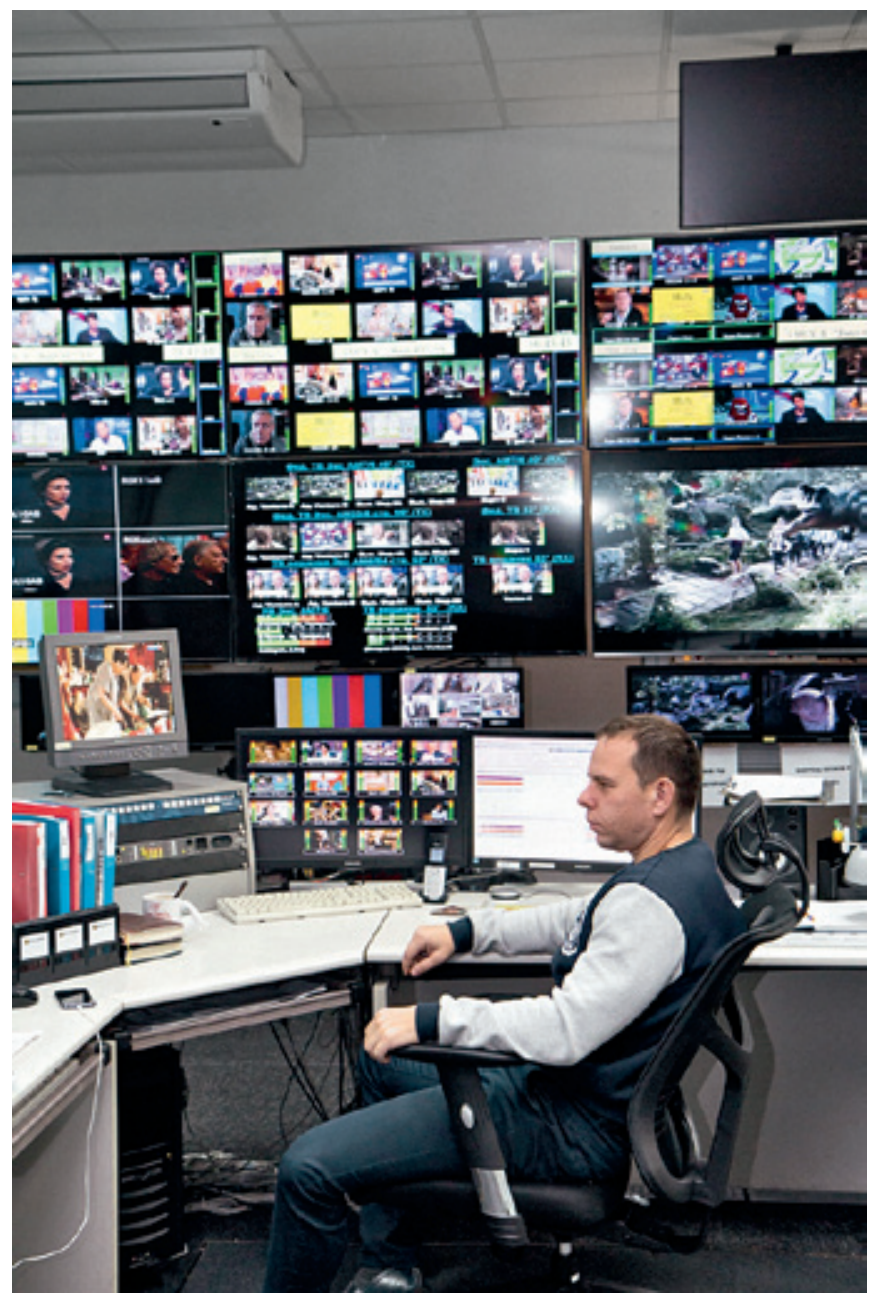

В ЦКС "Медвежьи Озера" работают квалифицированные специалисты, прошедшие обучение и стажировку в фирмах MCL, Miteq, Andrew, ECI, Thomson, Juniper Networks.

Высокий профессионализм специалистов, работающих на предприятии, современное техническое оснащение самым новейшим оборудованием, налаженные многолетние контакты и тесное взаимодействие с операторами и производителями аппаратуры, огромный опыт по организации каналов спутниковой связи позволяют ЦКС "Медвежьи Озера" активно сотрудничать с ведущими российскими и зарубежными компаниями в области телевизионных и телекоммуникационных услуг, а также качественно и надежно обеспечивать государственное цифровое телерадиовещание на 11 часовых зон и предоставлять услуги связи на территории Российской Федерации и за ее пределами.

Подготовлено по материалам ФГУП "Космическая связь" 